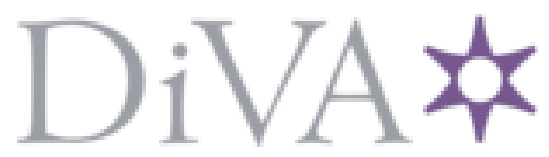

http://www.diva-portal.org

\title{
Postprint
}

This is the accepted version of a paper published in International Journal of Nursing Studies. This paper has been peer-reviewed but does not include the final publisher proof-corrections or journal pagination.

Citation for the original published paper (version of record):

Lundman, B., Viglund, K., Aléx, L., Jonsén, E., Norberg, A. et al. (2011)

Development and psychometric properties of the Inner Strength Scale.

International Journal of Nursing Studies, 48(10): 1266-1274

http://dx.doi.org/10.1016/j.ijnurstu.2011.03.006

Access to the published version may require subscription.

N.B. When citing this work, cite the original published paper.

Permanent link to this version:

http://urn.kb.se/resolve?urn=urn:nbn:se:esh:diva-2520 


\section{Development and psychometric properties of the Inner Strength Scale}

Berit Lundman ${ }^{\mathrm{a}}$, Kerstin Viglund ${ }^{\mathrm{a}}$, Lena Aléx ${ }^{\mathrm{a}}$, Elisabeth Jonsén ${ }^{\mathrm{a}}$, Astrid Norberg ${ }^{\mathrm{a}, \mathrm{b}}$, Regina Santamäki Fischer ${ }^{\mathrm{a}, \mathrm{c}}$, Gunilla Strandberg ${ }^{\mathrm{d}}$, Björn Nygren ${ }^{\mathrm{a}}$

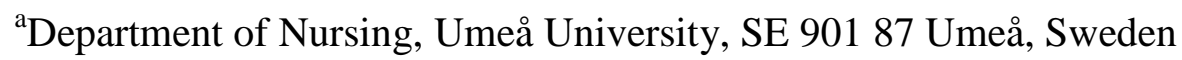

${ }^{\mathrm{b}}$ Department of Palliative Care Research, Ersta Sköndal University College, Stockholm, Sweden

${ }^{\mathrm{c}}$ Department of Nursing Education, University of Applied Sciences, Mariehamn, Åland, Finland

${ }^{\mathrm{d}}$ Department of Nursing, Umeå University, SE 93187 Skellefteå, Sweden

Corresponding author:

Berit Lundman

Department of Nursing,

Umeå University

SE-901 87, UMEÅ

SWEDEN

Phone: +46907869852

E-mail: berit.lundman@nurs.umu.se 


\section{ABSTRACT}

Background: Four dimensions of inner strength were previously identified in a metatheoretical analysis: firmness, creativity, connectedness, and flexibility.

Objective: The aim of this study was to develop an Inner Strength Scale (ISS) based on those four dimensions and to evaluate its psychometric properties.

Method: An initial version of ISS was distributed for validation purpose with the Rosenberg Self-Esteem Scale, the Resilience Scale, and the Sense of coherence Scale. A convenience sample of 391 adults, aged 19 to 90 years participated. Principal component analysis (PCA) and confirmatory factor analysis (CFA) were used in the process of exploring, evaluating, and reducing the 63 -item ISS to the 20 -item ISS. Cronbach's alpha and test-retest were used to measure reliability.

Results: CFA showed satisfactory goodness-of-fit for the 20-item ISS. The analysis supported a four-factor solution explaining $51 \%$ of the variance. Cronbach`s alpha on the 20 -item ISS was 0.86 , and the test-retest showed stability over time $(r=0.79)$.

Conclusion: The ISS was found to be a valid and reliable instrument for capturing a multifaceted understanding of inner strength. Further tests of psychometric properties of the ISS will be performed in forthcoming studies.

Keywords: Inner Strength Scale, instrument development, Rosenberg Self-Esteem Scale, Sense of Coherence Scale, Resilience Scale 


\section{What is already known about the topic}

- Inner strength is a central personal resource that promotes wellbeing and helps people to overcome adversities.

- Various questionnaires aimed at measuring inner resources have been developed.

- Inner strength is composed of four dimensions: firmness, creativity, connectedness, and flexibility.

- Inner strength relies on the interaction of the four interrelated dimensions in varying degrees and relationships.

\section{What this paper adds}

- A new scale, the Inner Strength Scale, has been developed to estimate the four dimensions of firmness, creativity, connectedness, and flexibility.

- The Inner Strength Scale was found to have satisfactory validity and reliability.

- The Inner Strength Scale was found to be applicable to men and women of various ages.

\section{Introduction}

In a previous study we found statistically significant correlations between scores on the Resilience Scale (RS) (Wagnild and Young, 1993), the Sense of Coherence Scale (SOC) (Antonovsky, 1987), the Purpose in Life Scale (PIL) (Crumbaugh and Maholick, 1964), and the Self-Transcendence Scale (STS) (Reed, 1991) among people aged 85 years and over (Nygren et al., 2005). We concluded that these correlations indicate some common dimension of inner strength. Therefore, a meta-theoretical analysis of the concepts resilience sense of 
coherence purpose in life and self-transcendence was performed. The concept of hardiness was also included in the analysis due to its resemblance to the other concepts (Lundman et al., 2010).

The meta-theoretical analysis resulted in a model of inner strength composed of four dimensions: firmness, creativity, connectedness, and flexibility (Lundman et al., 2010). These dimensions, in varying relationships, reflect what we understand as the basis of inner strength: an outlook on life that accepts change as inevitable over the course of a lifetime. Life offers opportunities and rewards as well as difficulties and adversities; having inner strength means not only having both feet on the ground, but also being connected to others: to family, friends, and society, as well as to nature; perceiving a spiritual dimension to life, and being able to transcend one's self. Inner strength is the willingness to shoulder responsibilities for oneself and for others, to endure, and to deal with difficulties and adversities as they arise. To have inner strength is to be creative and flexible and to believe in one's own abilities to act, to make choices, and to influence life's trajectory in a meaningful direction. Having inner strength also means having the courage to continue to seek meaning in life despite adversities Being open to changing life circumstances is as essential as perceiving challenges and believing that life is worthy of engagement. The four dimensions of inner strength were seen as interrelated and interacting in various degrees when dealing with various life circumstances (Lundman et al., 2010).

In the literature there are various descriptions of inner strength, including as a central human resource that promotes well-being (Roux et al., 2002) and as a supportive power, with the capacity and potential for endurance, self-knowledge, growth, and wisdom (Dingley et al., 2000). In an ethnographic study inner strength was described as a process of growth and transition (Rutherford and Parker, 2003). Inner strength has also been described as the ability to fight and the motivation to go on and to do better (Haile et al., 2002). Nygren et al. (2007) 
found that making good choices (for oneself and for others) could be interpreted as one dimension of inner strength. Dingley and Roux (2003) identified five interrelated dimensions: drawing strength from the past, focusing on opportunities, being supported by others, knowing one's purpose, and nurturing one's spirit. Rose (1990) showed that inner strength has many interwoven and interconnected aspects and described it as a dynamic and complex phenomenon. Most of the research focusing on inner strength has been carried out on women (e.g. Kotarba et al., 2003; Moloney, 1995; Rose, 1990; Roux et al., 2002), especially women with chronic diseases (e.g. Haile et al., 2002; Koob et al., 2002).

Other scales and questionnaires that seem to measure similar concepts have been published, e.g. the Rosenberg Self Esteem Scale (Rosenberg, 1965), the Personal Resource Questionnaire (Weinert and Brandt, 1987), the Inner Strength Questionnaire (Lewis and Roux, 2009) and the Resourcefulness Scale (Zauszniewsky et al., 2006). These scales and questionnaires have different theoretical origins: the Rosenberg Self Esteem Scale is based on Rosenberg's theory of global self esteem; the Personal Resource Questionnaire is based on the theory of relational provisions of social support the Inner Strength Questionnaire stems from a middle range theory of inner strength, and the Resourcefulness Scale from Rosenbaum's theory about dimensions of resourcefulness (Rosenbaum, 1990).

To summarize, inner strength has been described in various ways, and most studies focusing on inner strength have been built on empirical data. The existing scales and questionnaires mentioned above were developed from a variety of theoretical backgrounds and have emphasized different aspects of inner strength. Because empirical overlaps indicate some common dimensions of inner strength between the various scales and questionnaires (Nygren, et al., 2005), meta-theoretical analyses were performed on similar "inner strength" concepts from different origins (Lundman et al., 2010). The results of these analyses 
constitute the basis for the development of an Inner Strength scale aimed at measuring inner strength through the capturing and displaying of multidimensional aspects of inner strength.

\section{Aim}

The aim of this study was to develop the Inner Strength Scale (ISS) and evaluate its psychometric properties.

\section{Methodology}

Upon completion of the meta-theoretical analysis by Lundman et al. (2010), the research group developed the new scale according to the following steps:

1. Based on the meta-theoretical analysis 114 items that could mirror inner strength were constructed; these 114 items were then reduced to 63 items.

2. The 63-item ISS was distributed to a convenience sample of people of different ages, together with three other scales for convergent validation purposes.

3. The present study was based on collected data from the 63-item ISS, and the ISS was further reduced to 20 items.

4. Goodness-of-fit of the model was tested, and the final 20-items ISS is presented.

\subsection{Initial development of the Inner Strength Scale}

The initial development was guided by the procedure described by Glasberg et al. (2006). Each member of the research team individually formulated several items for each of the four dimensions in the model of inner strength. The empirical indicators of the four dimensions 
were i.e. the major paradigms, the most prominent assumptions, the critical attributes and the characteristics of the concept that were the point of departure of the meta-theoretical analyse (resilience, sense of coherence, hardiness, purpose in life and self-transcendence) (Lundman et al., 2010). The researchers then individually sorted the 114 items according to the particular dimension they considered each item to reflect. Items placed in totally different dimensions were excluded due to overlaps and indistinctness (face validity). The remaining items were compared and discussed within the research group, resulting in a further reduction to 63 items, which were judged to be theoretically relevant as sensible or logical aspects of inner strength. Some items were reformulated in order to make them easier to understand. The 63item scale consisted of items related to the dimensions of firmness $(n=18)$, creativity $(n=1)$, connectedness $(n=18)$, and flexibility $(n=16)$. A Likert-type scale was used with response options ranging from 1 to 6 , where 1 represents "totally disagree", 2 "almost totally disagree", 3 "partly disagree", 4 "partly agree", 5 "almost totally agree", and 6 represents "totally agree."

\subsection{Participants}

The participants constituted a convenience sample of Swedish speaking people, above 18 years of age, including senior citizens, working adults, and students. Their ages ranged from19 to 90 years, with a mean age of $46.8(\mathrm{SD}=18.2)$. Numbers of participants in different age groups and by sex are shown in Table 1. The participants were mostly from northern Sweden, but also from other parts of Sweden and Åland, a Swedish-speaking area in Finland.

Please insert Table 1 about here 
The 63-item ISS was answered by 402 participants. In 11 cases more than three items were missing on some of the four scales; these cases were removed before analysis, leaving 391 participants for analysis; 222 (57\%) women, $153(39 \%)$ men, and $16(4 \%)$ who omitted answers for sex, age, or both. If fewer than three items per scale were unanswered, missing data was replaced with the mode value for the actual item. Thirty-one participants accomplished a test-retest with a three-week interval.

\subsection{Instruments for validation}

For convergent validation purposes three scales were used: the Rosenberg Self-Esteem Scale (RSE) (Rosenberg, 1965), the Resilience Scale (RS) (Wagnild and Young, 1993), and the Sense of Coherence Scale (SOC) (Antonovsky, 1987). The concepts of RS and SOC had been analyzed in the meta-theory analysis by Lundman et al. (2010) described above; the RSE was chosen because it also measures dimensions similar to those of inner strength, and it was not included in the meta-theory analysis.

Research on self-esteem has its origin in social psychology (Rosenberg, 1965). Rosenberg defines self-esteem as a component of the self-concept, an individual's positive or negative thoughts and feelings about her or his worth and importance. Self-esteem is considered a stable sense of worth or worthiness. Rosenberg's thoughts on self-esteem arise from the idea that people's attitudes towards themselves resemble their attitudes towards other objects. He claims that people's attitudes have a very strong effect on how they see themselves. The RSE is a 10-item Likert-type scale ranging from 1 to 4 , where 1 is "strongly agree" and 4 is "strongly disagree." The possible score ranges from 10 to 40 and a high score indicates a high level of self-esteem. Alpha coefficients ranging from 0.72 to 0.87 and test- 
retest correlations of 0.82 to 0.88 have been reported (Rosenberg, 1965). In the present study Cronbach's alpha was 0.83 .

Wagnild and Young (1993) developed the RS on the basis of a qualitative study among elderly women who had adapted successfully after major life-events (Wagnild and Young, 1990). The RS consists of 25 items where the respondents rate statements about their personal view of themselves on a Likert-type scale ranging from 1 to 7 . The total score ranges from 25 to 175 , and the higher the score, the higher the degree of resilience. The scale was translated into Swedish and psychometrically tested by Nygren et al. (2004) and Lundman et al. (2007). Alpha coefficients between 0.72 and 0.94 have been reported for the English version (Wagnild, 2009) and between 0.83 and 0.90 for the Swedish version (Nygren et al., 2004; 2005). In the present study Cronbach's alpha was 0.86 .

The SOC scale was developed with a focus on salutogenic theory (Antonovsky, 1987), which arose from interviews with people who had stayed healthy despite experiences in concentration camps. The SOC scale exists in two versions, a 29-item scale and a 13-item scale. In the present study the SOC-13 (Antonovsky, 1993) was used. The scale is consists of Likert-type items with response ranges from 1 to 7 . The range of possible score is 13 to 91 , and the higher the score, the stronger the sense of coherence. Langius and Björvell (1993) translated the scale into Swedish and found it psychometrically sound. For the Swedish 13item version, alpha coefficients between 0.74 and 0.91 have been reported (Langius and Björvell, 1993). In the present study Cronbach's alpha was 0.83 .

The 63-item ISS and the three other scales were distributed to, and collected from, the participants personally or by mail. In a letter enclosed with the scales the participants were asked to complete all of the scales and to give their comments on the ISS as a whole or on individual items. The letter also described the purpose of the study and assured confidentiality. 


\subsection{Statistical analysis}

Principal component analysis (PCA) and confirmatory factor analysis (CFA) were performed on the ISS in different stages of its development. PCA was used to explore the underlying structure of the 63-item ISS, with the main purpose to condense the scale, while CFA was performed on the condensed 20-item scale to evaluate the model fit. Prior to performing PCA and CFA, the suitability of data for factor analysis was assessed using Kaiser-Meyer-Oklin (KMO), a test of sampling adequacy, and Bartlett's test of sphericity, a test of the suitability of the correlation matrix for factor analysis.

During PCA the 63 items were forced onto a four-factor solution based on the theoretical model of inner strength (Lundman et al., 2010), followed by Direct Oblimin rotation. The reason for using Oblimin rotation was that the factors (dimensions) were conceptualized as interrelated aspects of inner strength (cf. DeVellis, 2003). Deletion of items from the 63-item ISS was performed in several steps using corrected item-total correlation, Cronbach's alpha if an item was deleted, factor loadings, participants' comments on the ISS, and theoretical considerations. Statistical criteria for item deletion were corrected item-total correlation below 0.3 (Ferketich, 1991), substantial improvement (>0.05) of Cronbach's alpha if the item was deleted (DeVellis, 2003), and factor loadings below 0.4 (Hair et al., 1998). When performing CFA on the final 20-item ISS, maximum likelihood estimation was used. Statistics used to assess goodness-of- fit were chi-square $\left(x^{2}\right)$ and chi-square/degrees of freedom $\left(x^{2} / \mathrm{df}\right)$, Tucker-Lewis Index (TLI), Comparative Fit Index (CFI), and Root Mean Square Error of Approximation (RMSEA).

Mean value and standard deviation, $t$-test, and ANOVA for the 20-item ISS for different age groups and by sex were calculated and are shown in Table 2. Internal consistency was 
estimated by Cronbach's alpha, and stability over time by a test-retest $(\mathrm{n}=31)$ correlation on the ISS, using Pearson's correlation coefficient. Convergent validity was estimated by correlating the scores from the four scales (ISS, RSE, RS, and SOC) using Pearson's correlation coefficient. The SPSS and AMOS statistical software package (version 17.0 for Windows) were used for statistical analysis.

Please, insert Table 2 about here

\section{Results}

\subsection{Item reduction}

Cronbach's alpha for the primary 63-item ISS was 0.92 . Convergent validity of the ISS was supported by correlation analysis with the three scales used for that purpose (see Table 3). The correlations were in the interval of 0.50 to 0.69 , with the highest between the ISS and the RS.

Please insert Table 3 about here

In the initial test of sample and data adequacy, the KMO value was 0.9, exceeding the recommended value of 0.6 (Kaiser, 1974), and Bartlett's test of sphericity reached statistical significance, supporting the factorability of data. PCA was performed on the 63-item ISS with a four-factor solution, using Oblimin rotation, based on the theoretical model. The scree plot supported the four-factor model, with four factors clearly above the "elbow" (DeVellis, 2003) explaining $35 \%$ of the variance. In the process of item reduction the criteria mentioned above 
were used. Eleven items that were below 0.3 in the corrected item-total correlation were removed, which left 52 items, and a new PCA was performed. Nineteen items were removed because of factor loading $<0.4$, unsupportive participants' comments, theoretical aspects, or any or all of the above, which left 33 items. A final 13 items were removed based upon their having the lowest factor loadings after four-factor Oblimin rotation, along with theoretical considerations, which left 20 items for use in the final scale.

\subsection{The 20-item ISS}

The final version of the ISS consisted of 20 items, with 5 items in each of the four dimensions (factors) of inner strength: firmness, creativity, connectedness, and flexibility. All items were phrased positively, and the scores ranged 20 to 120 with higher scores denoting higher degrees of inner strength. The analysis of the 20-item ISS was performed on the same data as the 63 items ISS. In the 20-item ISS the scree plot also supported four factors, with four factors clearly above the elbow explaining $51 \%$ of the variance. The factor loadings, total variance explained, mean inter-item correlation, and Cronbach's alpha in the final ISS are shown in Table 4.

Please insert Table 4 about here

Three items had double loadings $>0.4$ in the structure matrix: the item "I carry through on things that I have planned" loaded in firmness (0.52) and in flexibility (0.45); the item "I regard challenges as opportunities to develop" loaded in creativity (0.74) and in firmness (0.40); and the item "I feel open to life and its possibilities" loaded in creativity (0.69) and in connectedness (0.48). There were no double loadings in the pattern matrix. Cronbach's alpha 
for each of the factors was between 0.60 and 0.82 , with the lowest for flexibility, which also had the lowest mean inter-item correlation $(r=0.23)$ and the lowest total variance explained (6.1\%). Cronbach's alpha for the total final 20-item ISS was 0.86 , which is in the interval of very good internal consistency (DeVellis, 2003). The distribution of answers is presented in Table 5. The test-retest $(\mathrm{n}=31)$ on the 20-item ISS was $r=0.79$.

Please insert Table 5 about here

CFA was performed on the 20-item ISS to test its goodness-of-fit. The chi-square was significant $\left(x^{2}=333.2, \mathrm{df}=164, \mathrm{p}<0.000\right)$, however the relative chi-square $\left(x^{2} / \mathrm{df}\right)$, aimed to make a test less dependent on sample size, was 2.0, and the cut-off for good model fit was $\leq 2$ (cf. Ullman, 2001). The TLI was 0.90; CFI was 0.92 and exceeded the necessary 0.9 for acceptable model fit; and, finally, RMSEA was 0.05. The cut-off for good model fit is RMSEA $\leq 0.05$ (Browne and Cudeck, 1992). The model of the final 20-item ISS is shown in Figure 1, including the path coefficients (standardized regression weights and correlations). Correlations between the factors were in the interval of 0.47 to 0.68 , with the highest between firmness and flexibility. All of the path coefficients were significant on the $p<0.001$ level.

Please insert Figure 5 about here

\section{Discussion}

This study focused on the development and testing of psychometric properties of a scale aimed at measuring inner strength, the ISS. Development of the scale was inspired by 
empirical research on various aspects of inner strength among old people (e.g. Aléx et al., 2006; Nygren et al., 2007; Santamäki Fischer et al., 2008) and on a meta-theoretical analysis that resulted in the identification of four dimensions of inner strength: firmness, creativity, connectedness, and flexibility, with an understanding that inner strength relies on the interaction of these dimensions (Lundman et al., 2010).

The results of this study provide solid support for the reliability and validity of the ISS. The CFA was satisfactory in the goodness-of-fit test of the 20-item ISS model, showing acceptable model-fit values, with the exception of the chi-square, which was, however, shown to be appropriate for the sample size (DeVellis, 2003). The results also supported the four dimensions of inner strength proposed by the meta-theoretical analysis. That three items had double loadings $>0.4$ in the structure matrix seems reasonable and explainable, as the factors mirror dimensions of inner strength that are suggested to be interrelated. The strongest item loading determined the factor to which the item belonged, and this also seems logical based on the meta-theoretical analysis performed by Lundman et al. (2010).

In the process of reducing the initial 63-item ISS to the final 20-item ISS, a four-factor solution was supported by several performances of PCA, which on all occasions presented four factors clearly above the elbow (DeVellis, 2003). The flexibility factor was found to have the weakest support for its relevance, showing the lowest alpha coefficient, mean inter-item correlation, and total variance explained, but we considered it strong enough to stand on its own as a valuable dimension of inner strength. Further studies may contribute to the ongoing process of validation. Internal consistency based on Cronbach's alpha was adequate for both the 20-item ISS in total and for each of the four factors, especially considering that there were only five items in each of the factors.

The convenience sample consisted of a population aged 19 to 90 , and since the ISS is developed to be suitable for use in health care contexts, without any specific sample criteria 
(e.g. disease, illness, occupation, sex, or age), the sample seemed relevant to this initial psychometric test. As showed in Table 2 there was no significant difference in the mean scores of the ISS between the age groups in general, which could indicate that the ISS is useful irrespective of age, at least in adults. However, the youngest age group had the lowest mean score, which could also indicate that inner strength increases with age and is related to increased experience of various kinds. There was a significant difference between female and male participants in the mean scores of the ISS, with the higher scores for female participants. This was interesting because most of the earlier studies related to inner strength have been conducted on women only, and thus no comparison between sexes have been possible to make. Further studies may contribute to enhanced understanding of inner strength from a gender perspective.

The knowledge upon which the development of a scale is based is significant for both the credibility and the usefulness of the scale (DeVellis 2003). A strength of our meta-theoretical analysis is its inclusion of concepts resembling "inner strength" drawn from different origins (see above, Lundman et al., 2010). The meta-theoretical analysis suggests that the concepts were initially supposed to answer different questions: Resilience: What facilitates people bouncing back after adverse experiences? Sense of coherence: What facilitates people moving towards the healthy end of a health/disease continuum? Hardiness: What facilitates people resisting stressful events? Purpose in life: What facilitates people finding meaning in life? Self-transcendence: What facilitates people extending their boundaries?

These questions indicate that the answers may cover different aspects of inner strength and our theoretical analysis gave us a broad and multifaceted understanding of inner strength as a basis for the development of the scale. Furthermore, those who developed the concepts described above initially focused on different groups (e.g. different ages, sexes, and life situations). As the development of the scale has progressed as described, we argue that the 
ISS has a wide range of applications and can be tested for use on a variety of people, young and old, female and men, healthy and unhealthy.

\subsection{Methodological considerations}

The selection of the participants in the convenience sample could be seen as a limitation as only Caucasians, and more women than men, were enrolled. Further testing will show whether the ISS is valid in other, more limited, samples, e.g. among only elderly or unhealthy people. Inner strength is an abstract concept and it can be difficult to estimate it and to establish construct validity. However, we believe that the RS, the SOC, and the RSE all measure similar dimensions to the ISS and so we used them for convergent validation. Our careful meta-theoretical analysis with the identification of the four dimensions that compose inner strength has further developed the concept.

\subsection{Implications for nursing}

Scales have been used in nursing to assess such things as experience of pain, nutritional value, and development of ulcers. Assessing inner strength would provide information about less visible matters that probably have an impact on patients' capabilities, in spite of their frailty and weakness, and would be a help in the nursing process for patients retaining health or gaining health.

When nurses pay attention to the inner strength within every patient they will see the person as an agent behind their role as a patient. Understanding and supporting patients in maintaining contact with their family and friends and in continuing with activities that are important to them can help to enable connectedness. Support for creativity can be offered by 
being amenable to patients' suggestions and proposed solutions to problems concerning their treatment and care. Believing in and encouraging patients' decisions and choices about their illness and belief in recovery can be ways of supporting their firmness. Finally, support for flexibility can be given by believing that patients have inner strength even in illness and in late life and helping them to find hope in situations that seem hopeless.

\subsection{Conclusions}

The newly constructed ISS is a short and easily administrated scale for capturing a multifaceted understanding of inner strength among men and women of various ages. The scale was found to be valid and reliable. Further tests of psychometric properties of the ISS will be performed in forthcoming studies.

\subsection{Future research}

Besides further test of psychometric properties in various age groups and ethnic groups the ISS scale has potential to be valuable in clinical settings, for example, to elaborate the inner strength in relation to health, wellbeing, and physical and mental functioning. There is also a need for longitudinal studies where changes in inner strange can be related to various life circumstances.

\section{Ethical approval}

The study was approved by the Regional Ethics Review Board in Umeå, (Dnr 09-178M) 
Conflicts of interest: There were no conflicts of interests. 


\section{References}

Aléx, L., Hammarström, A., Norberg, A., Lundman, B., 2006. Balancing between dominating discourses - the art of being old and living as a Sami woman. Health Care for Women International 27(10), 873-892.

Antonovsky, A., 1987. Unravelling the mystery of health. How people manage stress and stay well. Jossey-Bass Publishers, London.

Antonovsky, A., 1993. The structure and properties of the sense of coherence scale. Social Science \& Medicine, 36(6), 725-733.

Browne, M.W., Cudeck, R., 1992. Alternative ways of assessing model fit. Sociological Methods and Research, 21(2), 230-258.

Crumbaugh, J.C., Maholick, L.T., 1964. An experimental study in existentialism. The psychometric approach to Frankl's concept of noogenic neurosis. Journal of Clinical Psychology, 20(2), 200-207.

DeVellis, R.F., 2003. Scale Development: Theory and Applications ( $2^{\text {nd }}$ ed.). Sage Publications, Thousand Oaks, CA.

Dingley, C.E., Roux, G., 2003. Inner strength in older Hispanic women with chronic illness. Journal of Cultural Diversity, 10(1), 11-22.

Dingley, C.E., Roux, G., Bush, H.A., 2000. Inner strength: a concept analysis. The Journal of Theory Construction \& Testing, 4(2), 30-35.

Ferketich, S., 1991. Focus on psychometrics. Aspects of item analysis. Research in Nursing \& Health, 14(2), 165-168.

Glasberg, A.L., Eriksson, S., Dahlqvist, V., Lindahl, E., Strandberg, G., Söderberg, A., Sørlie, V., Norberg, A., 2006. Development and initial validation of the Stress of Conscience Questionnaire. Nursing Ethics, 13(6), 181-193. 
Haile, B.L., Landrum, P.L., Kotarba, J.A., Trimble, D., 2002. Inner strength among HIVinfected women: nurses can make a difference. Journal of the Association of Nurses in AIDS Care, 13(39), 74-80.

Hair, J.F., Anderson, R.E., Tatham, R.L., Black, W.C., 1998. Factor analysis. In: Hair, J.F., Anderson, R.E., Tatham, R.L., Black, W.C. (Eds), Multivariate Data Analysis (5th ed.). Prentice Hall, Upper Saddle River, NJ.

Kaiser, H.F., 1974. An index of factorial simplicity. Psychometrika, 39(1), 31-36.

Koob, P.B., Roux, G., Bush, H.A., 2002. Inner strength in women dwelling in the world of multiple sclerosis. International Journal for Human Caring, 6(2), 20-28.

Kotarba, J.A., Haile, B., Landrum, P., Trimble, D., 2003. Inner strength and the existential self: improving managed care for HIV+ women through the integration of nursing and sociological concepts. Research in Sociology of Health Care, 21, 87-106.

Langius, A., Björvell, H., 1993. Coping ability and functional status in a Swedish population sample. Scandinavian Journal of Caring Sciences, 7(1), 3-10.

Lewis, K.L., Roux, G., 2009. Psychometric testing of the Inner Strength Questionnaire: women living with chronic health conditions. Applied Nursing Research, June 16 [Epub ahead print]. DOI:10.1016/j.apnr.2009.06.003

Lundman, B., Aléx, L., Jonsén, E., Norberg, A., Nygren, B., Santamäki Fischer, R., Strandberg, G., 2010. Inner strength - a theoretical analysis of salutogenic concepts. International Journal of Nursing Studies, 47(2), 251-260.

Lundman, B., Strandberg, G., Eisemann, M., Gustafson, Y., Brulin, C., 2007. Psychometric properties of the Swedish version of the Resilience Scale. Scandinavian Journal of Caring Sciences, 21(2), 229-237.

Moloney, M.F., 1995. A Heideggerian hermeneutical analysis of older women's stories of being strong. Image:Journal of Nursing Scholarship, 27(2), 104-109. 
Nygren, B., Aléx, L., Jonsén, E., Gustafsson, Y., Norberg, A., Lundman, B., 2005. Resilience, sense of coherence, purpose in life and self-transcendence in relation to perceived physical and mental health among the oldest old. Aging \& Mental Health, 9(4), 354-362.

Nygren, B., Björkman Randström, K., Lejonklou, A.K., Lundman, B., 2004. Reliability and validity of a Swedish language version of the Resilience Scale. Journal of Nursing Measurement, 12(3), 169-178.

Nygren, B., Norberg, A., Lundman, B., 2007. Inner strength as disclosed in narratives of the oldest old. Qualitative Health Research, 17(8), 1060-1073.

Reed, P., 1991. Toward a nursing theory of self-transcendence: deductive reformulation using developmental theories. Advances in Nursing Science, 13(4), 64-77.

Rose, J.F., 1990. Psychological health of women: a phenomenological study of women's inner strength. Advances in Nursing Science, 12(2), 56-70.

Rosenbaum, M., 1990. Learned Resourcefulness: On Coping Skills, Self-control, and Adaptive Behavior. Springer Publishing, New York.

Rosenberg, M., 1965. Society and the Adolescent Self-image. Princeton University Press, Princeton, NJ.

Roux, G., Dingley, C.E., Bush, H.B., 2002. Inner strength in women: metasynthesis of qualitative findings in theory development. The Journal of Theory Construction \& Testing, 6(1), 86-93.

Rutherford, M.S., Parker, K., 2003. Inner strength in Salvadoran women: A secondary analysis. Journal of Cultural Diversity, 10(1), 6-10.

Santamäki Fischer, R., Norberg, A., Lundman, B. 2008. Embracing opposites: meaning of growing old as narrated by people aged 85. The International Journal of Aging \& Human Development, 67(3), 259-271. 
Ullman, J.B., 2001. Structural equation modeling. In: Tabachnick, B.G., Fidell, L.S. (Eds), Using Multivariate Statistics (4th ed.) Allyn \& Bacon, Needham Heights, MA., pp. 653771.

Wagnild, G.M., 2009. A review of the Resilience Scale. Journal of Nursing Measurement, 17(2), 105-113.

Wagnild, G.M., Young, H.M., 1990. Resilience among older women. Image: Journal of Nursing Scholarship, 22(4), 252-255.

Wagnild, G.M., Young, H.M., 1993. Development and psychometric evaluation of the Resilience Scale. Journal of Nursing Measurement, 1(2), 165-178.

Weinert, C., Brandt, P.A., 1987. Measuring social support with the Personal Resource Scale. Western Journal of Nursing Research, 9(4), 589-602.

Zauszniewsky, J.A., Lai, C.Y., Tithiphontumrong, S., 2006. Development and testing the Resourcefulness Scale for Older Adults. Journal of Nursing Measurement, 14(1), 57-68. 
Table 1. Characteristics of participants by age and sex

\begin{tabular}{llll}
\hline & Female & Male & Total \\
Age & $\mathrm{n}$ & $\mathrm{n}$ & $\mathrm{n}$ \\
\hline $19-29$ & 43 & 52 & 95 \\
$30-39$ & 31 & 22 & 53 \\
$40-49$ & 36 & 18 & 54 \\
$50-59$ & 44 & 25 & 69 \\
$60-69$ & 39 & 19 & 58 \\
$70-79$ & 16 & 14 & 30 \\
$\geq 80$ & 13 & 3 & 16 \\
Missing data & & & 16 \\
\hline
\end{tabular}


Table 2. Mean scores on the 20-item ISS by age groups and sex

\begin{tabular}{llll}
$\mathrm{S}$ & $\mathrm{n}$ & mean $(\mathrm{SD})$ & $F^{l}$ or $t^{2}(p)$ \\
\hline Age & & & \\
$19-29$ & 95 & $96(9.8)$ & $1.964(.07)$ \\
$30-39$ & 53 & $99(11.2)$ & \\
$40-49$ & 54 & $100(8.3)$ & \\
$50-59$ & 69 & $99.8(8.5)$ & \\
$60-69$ & 58 & $100.3(10)$ & \\
$70-79$ & 30 & $97.4(9.5)$ & \\
$\geq 80$ & 16 & $98.8(10.1)$ & \\
Total & 375 & $98.6(9.7)$ \\
Sex & & & \\
Female & 222 & $99.8(9.8)$ \\
Male & 153 & $96.7(9.3)$ \\
\hline
\end{tabular}

\footnotetext{
${ }^{1}$ Analysis of variance (ANOVA)

${ }^{2}$ Students t-test
} 
Table 3. Correlations of the four scales, using Pearson's correlation coefficient

\begin{tabular}{lllll}
\hline & \multicolumn{5}{c}{ Correlations } \\
& RSE & RS & SOC & ISS \\
\hline RSE & - & & & \\
RS & $.535^{* *}$ & - & & \\
SOC & $.573^{* *}$ & $.509 * *$ & - & \\
ISS & $.503^{* *}$ & $.691 * *$ & $.528^{* *}$ & - \\
\hline$* * \mathrm{p}<0.01(2$-tailed $)$ & & &
\end{tabular}


Table 4. ISS items, factor loadings, total variance explained, mean inter-item correlations, and Cronbach's alpha.

\begin{tabular}{|c|c|c|c|c|c|c|c|c|}
\hline \multirow[b]{2}{*}{ Items } & \multicolumn{2}{|c|}{ Firmness } & \multicolumn{2}{|c|}{ Creativity } & \multicolumn{2}{|c|}{ Connectedness } & \multicolumn{2}{|c|}{ Flexibility } \\
\hline & Pattern $^{2}$ & Structure $^{3}$ & Pattern $^{2}$ & Structure $^{3}$ & Pattern ${ }^{2}$ & Structure $^{3}$ & Pattern $^{2}$ & Structure $^{3}$ \\
\hline I know my responsibility $\left(16^{1}\right)$ & .709 & .739 & & & & & & \\
\hline I value my independence highly $\left(10^{1}\right)$ & .700 & .701 & & & & & & \\
\hline I have both feet on the ground $\left(18^{1}\right)$ & .679 & .723 & & & & & & \\
\hline I am a person who can be trusted $\left(13^{1}\right)$ & .678 & .700 & & & & & & \\
\hline I carry through on things that I have planned $\left(5^{1}\right)$ & .400 & .517 & & & & & .322 & .450 \\
\hline I think it is exciting to try new things $\left(3^{1}\right)$ & & & -.817 & -.784 & & & & \\
\hline I am interested in learning new things $\left(20^{1}\right)$ & & & -.766 & -.776 & & & & \\
\hline I think it is important to dare to face challenges $\left(15^{1}\right)$ & & & -.732 & -.744 & & & & \\
\hline I regard challenges as opportunities to develop $\left(12^{1}\right)$ & .146 & .401 & -.726 & -.773 & & & & \\
\hline I feel open to life and its possibilities $\left(8^{1}\right)$ & & & -.591 & -.695 & -.274 & -.482 & & \\
\hline I seek support from other people when I have difficulty $\left(19^{1}\right)$ & & & & & -.808 & -.765 & & \\
\hline I feel solidarity with other people $\left(14^{1}\right)$ & & & & & -.717 & -.776 & & \\
\hline I accept support from others when I need it $\left(6^{1}\right)$ & & & & & -.715 & -.731 & & \\
\hline
\end{tabular}


I see myself as part of a context $\left(9^{1}\right)$

I have patience $\left(17^{1}\right)$

I can usually let go of an injustice that affects me $\left(11^{1}\right)$

I can accept criticism $\left(4^{1}\right)$

I accept that the world is not always fair $\left(7^{1}\right)$

Total variance explained (\%)

Mean inter-item correlation

\section{Cronbach's alpha}

${ }^{1}$ The item number on the ISS and in Figure 1. Note: The English translation of the items has not been psychometrically tested

${ }^{2}$ The regression coefficients for each variable on each factor in the data

${ }^{3}$ The correlation coefficients for each variable on each factor in the data 
Table 5. Median, inter-quartile range (iqr) and distribution in percent for each item

\begin{tabular}{|c|c|c|c|c|c|c|c|}
\hline & & \multicolumn{5}{|c|}{$\begin{array}{l}\text { Totally } \\
\text { disagree }\end{array}$} & \multirow{2}{*}{\begin{tabular}{|l} 
Totally \\
agree \\
6 \\
(\%) \\
\end{tabular}} \\
\hline Items & Md (iqr) & 1 & 2 & (\%) & (\%) & (\%) & \\
\hline $\begin{array}{l}\text { I know my responsibility } \\
\text { Jag vet vad som hör till mitt ansvar }\end{array}$ & $5.0(1.0)$ & 0.5 & 0.5 & 1.5 & 11.5 & 45 & 41 \\
\hline $\begin{array}{l}\text { I value my independence highly } \\
\text { Jag värderar min självständighet högt }\end{array}$ & $5.0(1.0)$ & 0.5 & 0.5 & 4 & 14 & 36 & 45 \\
\hline $\begin{array}{l}\text { I have both feet on the ground } \\
\text { Jag är en person som har båda fötterna på jorden }\end{array}$ & $5.0(1.0)$ & 0.5 & 0.5 & 3 & 14 & 44 & 38 \\
\hline $\begin{array}{l}\text { I am a person who can be trusted } \\
\text { Jag är en person som man kan lita på }\end{array}$ & $6.0(1.0)$ & 0 & 0.5 & 0 & 4.5 & 39 & 56 \\
\hline $\begin{array}{l}\text { I carry through things that I have planned } \\
\text { Jag genomför det jag planerat }\end{array}$ & $5.0(1.0)$ & 0.5 & 1 & 4 & 24 & 50 & 21 \\
\hline $\begin{array}{l}\text { I think that it is exciting to try new things } \\
\text { Jag tycker det är spännande att prova på nya saker }\end{array}$ & $5.0(2.0)$ & 0 & 1.5 & 5 & 22 & 38.5 & 33 \\
\hline $\begin{array}{l}\text { I am interested in learning new things } \\
\text { Jag är intresserad av att lära mig nya saker }\end{array}$ & $5.0(1.0)$ & 0.5 & 0.5 & 2 & 14 & 41 & 42 \\
\hline $\begin{array}{l}\text { I think it is important to dare to accept challenges } \\
\text { Jag tycker att det är viktigt att våga anta utmaningar }\end{array}$ & $5.0(2.0)$ & 0 & 1 & 5 & 22 & 35 & 37 \\
\hline $\begin{array}{l}\text { I regard challenges as opportunities to develop } \\
\text { Jag ser på utmaningar som en möjlighet att utveckla }\end{array}$ & $5.0(2.0)$ & 0.5 & 1.5 & 5 & 21 & 39 & 33 \\
\hline $\begin{array}{l}\text { I feel open to life and its possibilities } \\
\text { Jag känner öppenhet inför livet och dess möjligheter }\end{array}$ & $5.0(2.0)$ & 0 & 1 & 6 & 21 & 41 & 31 \\
\hline I seek support from other people when I have & $4.0(1.0)$ & 1 & 6 & 14 & 32 & 28 & 19 \\
\hline
\end{tabular}




\begin{tabular}{|c|c|c|c|c|c|c|c|}
\hline $\begin{array}{l}\text { difficulty } \\
\text { Jag söker stöd av andra människor när jag har } \\
\text { svårt }\end{array}$ & & & & & & & \\
\hline $\begin{array}{l}\text { I feel solidarity with other people } \\
\text { Jag känner samhörighet med andra människo }\end{array}$ & $5.0(1.0)$ & 1 & 0.5 & 2.5 & 18 & 44 & 34 \\
\hline $\begin{array}{l}\text { I accept support from others when I need it } \\
\text { Jag kan ta emot stöd från andra när jag behöv }\end{array}$ & $5.0(2.0)$ & 0 & 0.5 & 6 & 21 & 33.5 & 38 \\
\hline $\begin{array}{l}\text { I see being with other people as meaningful } \\
\text { Jag tycker att det känns meningsfyllt att umga } \\
\text { andra människor }\end{array}$ & $6.0(1.0)$ & 0.5 & 0.5 & 2 & 10 & 33 & 54 \\
\hline $\begin{array}{l}\text { I see myself as part of a context } \\
\text { Jag ser mig själv som en del i ett sammanhang }\end{array}$ & $5.0(2.0)$ & 1.5 & 2 & 6 & 17.5 & 39 & 34 \\
\hline $\begin{array}{l}\text { I have patience } \\
\text { Jag har tålamod }\end{array}$ & $5.0(1.0)$ & 0 & 3 & 11 & 30 & 37 & 19 \\
\hline $\begin{array}{l}\text { I can usually let go of injustice that affects me } \\
\text { Jag kan vanligtvis släppa oförrätter som drabk }\end{array}$ & $4.0(2.0)$ & 2 & 9 & 18 & 37 & 29 & 5 \\
\hline $\begin{array}{l}\text { I can accept criticism } \\
\text { Jag kan "förhålla mig" till kritik som riktas mo }\end{array}$ & $4.0(1.0)$ & .5 & 2 & 10 & 43 & 38 & 6.5 \\
\hline $\begin{array}{l}\text { I accept that the world is not always fair } \\
\text { Jag inser att världen inte är rättvis och kan ha } \\
\text { detta }\end{array}$ & $5.0(2.0)$ & 1 & 3 & 5 & 20 & 40 & 31 \\
\hline $\begin{array}{l}\text { I can easily see things from different angles } \\
\text { Jag har lätt för att se saker och ting från olika } \\
\text { synvinklar }\end{array}$ & $5.0(2.0)$ & 0.5 & 0.5 & 4 & 27 & 43 & 25 \\
\hline
\end{tabular}




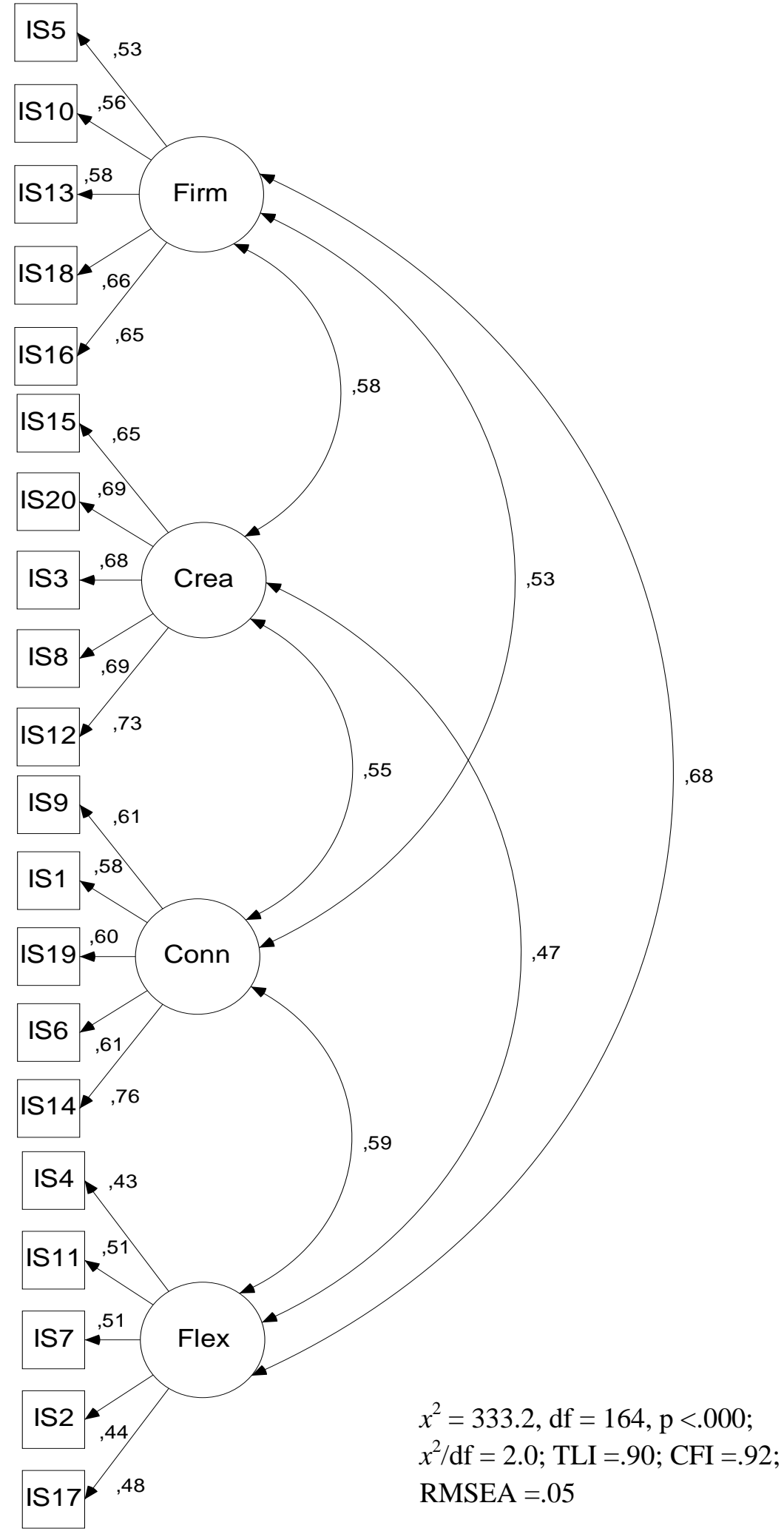

Figure 1. Model of the 20 item ISS with standardized regression weights and correlations 
